\title{
Cascading Morality After Dewey: A Proposal for a Pluralist Meta-Ethics with a Subsidiarity Hierarchy
}

\author{
Mark Coeckelbergh \\ Department of Philosophy, University of Vienna, Austria \\ mark.coeckelbergh@univie.ac.at
}

\begin{abstract}
In response to challenges to moral philosophy presented by other disciplines and facing a diversity of approaches to the foundation and focus of morality, this paper argues for a pluralist meta-ethics that is methodologically hierarchical and guided by the principle of subsidiarity. Inspired by Deweyan pragmatism, this novel and original application of the subsidiarity principle and the related methodological proposal for a cascading meta-ethical architecture offer a "dirty" and instrumentalist understanding of meta-ethics that promises to work, not only in moral philosophy but also in the (rest of the) real world, and that facilitates collaboration with other disciplines outside moral philosophy.
\end{abstract}

\section{Keywords}

meta-ethics - morality - pluralism - Dewey - subsidiarity - naturalism - Hume - Kant - postmodernism

\section{Introduction}

Anyone who aims to engage with moral philosophy in an interdisciplinary way is confronted with at least the following tensions or challenges when it comes to meta-ethical orientations and foundations, that is, approaches concerning what morality is, what moral sentences mean, and what the foundation of morality is, rather than normative questions, judgements, and theories about what is moral. Or, to put it in a language that takes into account the linguistic 
turn in 2oth century philosophy: If meta-ethics is what Gewirth (1968) called a 'second-order' discourse about first-order moral discourse, then what are the problems for participants in that discourse who wish to talk to people from other disciplines inside and outside philosophy?

First, there are challenges that are often seen as external to moral philosophy proper when it comes to their source and nature. On the one hand, there is the naturalist - moralist tension, with the naturalist challenge coming from the natural sciences, cognitive sciences, and engineering departments. "Why do you, moral philosopher, still care about reasons, free will, etc. if neuroscience shows $\mathrm{x}, \mathrm{y}$, and z.? And why hang on to your human nature if machines can also reason, or if machines can replace reasoning by statistical calculation?" In response, it seems that philosophers can go either the naturalist direction, as for example Daniel Dennett does, or stubbornly insist on a Kantian view, stressing the special status of moral reasons, moral obligations, etc.

On the other hand, there are challenges coming from the humanities and social science departments (including philosophy departments but also literature and politics departs for example), in particular those where postmodern and posthumanist thinking tend to flourish. "Why do you ask questions concerning individual morality and reasons if what really counts are political injustices and exclusions on the basis of identity? Why continue within a tradition of white men thinking about the moral science of 'man'? And how arrogant of you to focus on humans alone; you are excluding other entities!" Here we see also two responses that seem equally mutually exclusive: many (analytic) philosophers choose simply to ignore these directions of thinking and exclude them from the domain of moral philosophy, whereas others (usually so-called continental philosophers) embrace them, but often without looking back at mainstream moral philosophy, which is still discussing Hume and Kant.

Second, internally, that is, within moral philosophy itself, there are various kinds of meta-ethical approaches. For example, there are tensions between Humean and Kantian views of the foundation of morality. Here too philosophers tend to safely keep to their own particular moral-philosophical tradition. When dealing with a moral problem in an interdisciplinary context, then, one typically starts from a particular moral-philosophical tradition and applies this to the problem at hand. For example, one starts from virtue ethics and the applies this to animals or robots.

But are there other ways to deal with these challenges? How can interdisciplinary moral philosophers get out of these deadlocks?

One way is to come down on one approach and in a sophisticated way try to deal with the challenges coming from the "other" side. For example, compatibilist responses to the question of free will do this to the extent that they respond 
to natural sciences while hanging on to the notion of free will. Daniel Dennett is a good example here: as a philosopher and cognitive scientist, he argues that we have free will, but this free will is given by our evolved minds (Dennett 2003) and chance, next to deliberation, plays a role in decision-making processes. And some moral philosophers at least discuss theories of justice in a way that takes into account for instance postmodern feminist theory and the social sciences. For example, one could understand the work of Martha Nussbaum as being connected to several of these directions: the capability approach she developed with Amartya Sen is connected to several moral theories and social sciences, and Nussbaum's work on justice (e.g. Nussbaum 2006) seems to combine Humean elements (e.g. moral sentiment, imagination) and other, for example feminist, intuitions (e.g. about race and gender) - although the relation between these different theoretical directions is hardly theorized. All these attempts at connection and compatibility are admirable from the perspective of interdisciplinary moral philosophy.

But there is also another way of dealing with this variety of meta-ethical and interdisciplinary directions: a pluralist approach. But what is this? What does it mean with regard to meta-ethics? Does it mean that we have a choice between the different approaches? Does it mean that all of them are applied, and if so, how does that work?

This paper explores what a pluralist approach could mean. In particular, I argue for a pluralist meta-ethics guided by the subsidiarity principle.

First I outline three approaches to the foundation and core of morality: a naturalist one that has its roots in Hume, a rationalist one that has its root in Kant, and a poststructuralist and postmodern one that politicizes morality. The naturalist and postmodernist approaches question the boundaries (and hence the internal/external line) drawn by the rationalist, Kantian approach to morality. Then I argue for a pluralist approach that, roughly inspired by Dewey, further deconstructs the external/internal distinction and encompasses all three approaches, but involves a specific sequences and hierarchy justified by the principle of subsidiarity, here used as a meta-ethical principle. Influenced by Dewey, I argue that this can guide meta-ethical reflections by (interdisciplinary) moral philosophers but that it may also have some use in actually dealing with moral problems. I conclude that this is precisely the purpose: we need an instrumental, "dirty" meta-ethics that is not purified from moral experience.

Next to relying on the subsidiarity principle and on Deweyan thinking to support my argument, I also use and critically treat technological and naturalist metaphors such as algorithm and cascade in order to show the import of my claims. I also reflect on the role of language in my conclusion. Furthermore, in terms of literature references, my focus will be on contemporary literature that 
engages with Dewey's ethics, in so far that this literature helps me to argue for the meta-ethical methodology I propose. It is not my purpose to present an exegesis of Dewey's ethics, let alone that the scope of the paper would allow for a more comprehensive presentation or substantial engagement with the Humean, Kantian, and postmodern approaches summarized in the first part of the paper.

\section{2 \\ Three Approaches to the Foundation and Nature of Morality}

With regard to the question concerning the foundation and focus point of morality, we may broadly distinguish between three approaches: two modern, mainstream and one more recent, postmodern. I am aware that my brief summaries cannot do full justice to these approaches and to the variety within these approaches, the description of which remains at a very general level, but my purpose is to set us up for the main argument of the paper.

Naturalizing and psychologizing morality. A first approach, which ranges from Hume's theory of moral sentiments to today's attempts to combine moral theory and neuroscience, naturalizes and psychologizes morality. The idea is that our feelings and imagination, our capacity for empathy, our tendency to cooperate with others, and other natural, social, and cognitive capacities of human beings are the best basis for morality, since unlike reasons, they are truly motivating us to act in moral ways. This approach is rooted in an optimistic view of human nature and morality.

Often this approach is traced back to the work of David Hume. Against Hobbes, who thought that human nature, if unrestrained, leads to a violent state, Hume thinks that in a state of nature there would be both cooperation and self-interest.

Responding to the discussions of his time but also in line with Aristotle's grounding of virtue and eudaimonia in human nature, Hume thought that morality is derived from what he called the 'moral sentiments': feelings of approval and disapproval. The foundation of our moral norms lies in these natural-social sentiments. We evaluate other persons and their character (virtue) by means of moral sentiments, we feel approval. We also see advantage for others. And we can exercise 'sympathy' towards strangers: we can feel enjoyment when a trait is beneficial or agreeable. Hume writes in An Enquiry Concerning the Principles of Morals (1751) that what 'pronounces characters and actions amiable or odious, praise-worthy or blameable' depends in the final instance 'on some internal sense or feeling, which nature has made universal in the whole species.' (Hume 1751, 173) He emphasizes our shared humanity and in particular 'the human heart', the 'affection of humanity' (272-273). 
Note that a Humean approach does not exclude rational considerations: according to Hume, correction is sometimes necessary by rational considerations. And in his The Theory of Moral Sentiments (1759), Adam Smith added the idea of the impartial spectator to the moral sentimentalism tradition: individuals can examine their own conduct by imagining looking at themselves from an objective, outside point of view. But sympathetic sentiments remain the focus and source of morality.

From a social psychology point of view, one could also add habits here that, in order to make people more moral, we could stimulate not only the moral sentiments and imagination, but also train good habits. This could not only be related to Dewey (see below) but also to sociological work, in particular Bourdieu, who has a lot to say about habits as a nexus between the individual and society.

In general, this approach to what morality is, is compatible with the natural and social sciences. Philosophers such as Dennett who offer a naturalist understanding of traditional moral and other concepts such as free will and consciousness may have specific problems of giving a particular account, but they do not have a problem in principle with taking on this kind of project, given the openness for empirical work that is already built into this approach. As Hume puts it: philosophers should 'reject every system of ethics, however subtle or ingenious, which is not founded on fact and observation.' (Hume 1751, 175)

Rationalizing morality. A second approach, often rooted in Kant but also extending to other modern normative theories such as consequentialism and rationalistic interpretations of virtue ethics, views morality as independent from human nature and sociality - or at least from its empirical dimensions. Socrates already argued in the Republic that there are independent moral standards. In its Kantian version, this approach insists that morality is a realm that is and should be kept separate and unpolluted by empirical claims about human nature or about the functioning about our brains, biology, and so on. It seeks a foundation in reasons, principles, and/or moral obligations that stand apart from whatever may be the case about human beings and human societies. Normative theories in ethics and political philosophy, such as theories of justice, should guide our behaviour. This approach is pessimistic about human nature and morality: left unguided, people will not do the right thing. We better provide them with categorical obligations or reliable methods of moral calculation.

Here, too, morality is based upon a single foundation: rationality. Moreover, often philosophers in this Kantian tradition argue that what they are dealing with is morality strictly speaking; the Humean approach is too much about "is" and too little about "ought" (as they understand it). Whatever else is in 
our human nature and whatever other capacities we may have as biological human beings, we have reason and rational capacities and these and these alone should form the basis of morality. The rest is not moral but natural or pragmatic. Morality is thus rationalized.

Its focus on the metaphysical exclusivity and transcendence of morality renders this approach far less compatible with the natural and social sciences (except perhaps logic and very formal approaches), since it reserves (occupies) the terms "moral" and "morality" for a special domain (their domain) that is seen as clearly distinguished from the non-moral, naturalist and pragmatic domain. There is a world of moral reasons, moral principles, moral theories, etc. and there is a natural world, and both worlds do not really meet. Naturalistic explanations, according to this view, are not relevant at all to morality strictly speaking. Kant thought that moral philosophy must be concerned with a priori moral principles and their foundation: fundamental issues of morality must be addressed 'without drawing on observations of human beings and their behaviour' (Johnson and Cureton 2016). Morality concerns human beings only in so far as they are rational agents in an intelligible world; they then cause things in the sensible world and moral principles make demands on human psychology and social interactions, but morality is about that rational will and its principles.

In the Groundwork, for example, Kant acknowledges that ethics has an empirical part (which he calls practical anthropology) but he is concerned with the rational part which 'could properly be called morals.' (Kant 1785, 4) His metaphysics of morals must therefore be 'carefully cleansed of everything empirical.' (4-5) In contrast to Hume, he asserts that the ground of moral obligation does not lie 'in the nature of the human being or the circumstances of the world in which he is placed, but a priori solely in concepts of pure reason'; moral philosophy rests on that pure part (5).

Politicizing morality. A third approach, emerging in poststructuralist, constructivist, and postmodern thinking (and perhaps originally based on Marx and Nietzsche), present in Foucault (e.g. 1980), Deleuze, etc., thriving in contemporary feminism, and connecting to the social and cultural sciences, questions the universal human nature and the universality of morality presupposed in the other approaches. It calls attention to differences, identity, and power. The moral question here does not only concern what to do and how to justify what to do, but also and mainly who asks whom to do what. Who is the moral subject and who is subjected? Who are the moral agents and patients? Who is exercising power over whom? Moreover, posthumanists (including feminist posthumanists such as Haraway (e.g. 1991) and Braidotti) have questioned what they see as the anthropocentric bias of the other approaches: they 
argue that the "who" also includes non-humans and that modern approaches to morality have unjustly excluded animals and perhaps even (some?) technologies from the moral realm. This approach thus does not psychologize or rationalize morality but politicizes it.

Here the question is not whether morality must be founded upon sentiment (or more generally natural capacities) or rationality, but rather about whose sentiment and rationality this is and to whom or what it is applied. It takes seriously' Thrasymachus's argument in Plato's Republic (1953) that morality is about power, while diverging on the normative implications of this insight. For example, Nietzsche connected morality to the will to power, but that does not mean that contemporary postmodern feminism therefore accepts the current power distribution(s).

Again philosophers working within the second, Kantian approach will try to dismiss this approach as having little or nothing to do with morality strictly speaking; instead, they will argue, it is about politics, identity, power, and so on. Moreover, this third approach is compatible with the social sciences but not necessarily with the natural sciences, whose methodologies tend to lack room for more constructivist and postmodern epistemologies. If one chooses this third approach, it may become difficult to talk to natural scientists and engineers, for instance.

\section{3}

\section{A Pluralist Meta-Approach, Inspired by Dewey}

But do we have to choose? As suggested in my introduction, usually meta-ethical discussions are limited to conflicts between two approaches, for example between Humean and Kantian approaches or between universal theories of justice and identity-oriented approaches to justice. More generally, the meta-ethical problem seems to be described as a choice between the three approaches: which approach to choose? But what happens if we embrace a pluralist meta-ethical view, which encompasses all three approaches? What does that mean?

If applied at all, pluralism is usually employed at the level of normative moral theories. The source of inspiration from the history of moral philosophy is John Dewey, who argued in 'Three Independent Factors in Morals' (1930) that good, duty, and virtue all connect to moral experience. Dewey argued against the reductionism and one-sidedness of teleological, deontological, and virtue theories. Tensions between them cannot be resolved in theory but must be resolved in a particular situation, in which one of the factors will turn out to be relevant. The answer to the question whether we must choose between 
theories is then: we don't have to, and should not, choose on beforehand. All depends on the situation. As Pappas (2008) puts it when clarifying the normative standpoint of pragmatism: 'the normative issue is about how one should interact in moral situations', that is, the inquiry 'starts from where we are' (71). Dewey's normative theory does not start from an Archimedian or God's-eye point of view.

Dewey's argument is about moral theory. But we could also apply pluralism to meta-ethics and the approaches outlined, keeping in mind another Deweyan interest: the aim to sketch a meta-ethics that actually functions and does somehow justice to human moral experience. Moreover, it would be great if we do not just say "there is a truth in all three approaches and we should apply all of them" but if we can spell out some kind of relation between the approaches in a way that gives us some more meta-ethical guidance.

\section{Proposal for a Meta-Ethical Safety Architecture Based on the Principle of Subsidiarity}

Main argument. My intuition is that this can be done if we treat the approaches as steps in a kind of meta-ethical safety architecture: first we should try the first approach, if that doesn't work then the second approach, and if that in turn fails we should turn to the third approach. In meta-ethical practice this could mean, for example, that we follow this sequence or cascade: first we hope that people will sympathize with one another and cooperate, if that doesn't work we have to argue with them and use some normative principles and theories for this purpose, and if that fails we need to examine and change the underlying power structures that render natural sympathy and moral reasoning powerless by already excluding people and other entities before the moral reasoning or sympathy can even start off. I sense that this sequential way of thinking does not only represent some developments in the actual history of modern moral philosophy, but can also give us some practical guidance with regard to the role of morality in society by giving us a kind of meta-level algorithm for dealing with moral problems as philosophers (and perhaps even as moral agents and citizens).

How can this intuition be supported? I draw on two sources: one is political theory and another is American pragmatism.

For a start, I propose that we rely on a principle that is usually employed in a specific area of political thinking but deserves a much wider application in meta-ethics and normative thinking in general: the principle of subsidiarity. Usually the subsidiarity principle is meant to regulate political organization, 
most often the political organization within a nation state. It holds that political issues should be dealt with at the level at which the issues can (best) be resolved. For example, Føllesdal (1998) defines the principle as follows:

"The "principle of subsidiarity" regulates authority within a political order, directing that powers or tasks should rest with the lower-level sub-units of that order unless allocating them to a higher-level central unit would ensure higher comparative efficiency or effectiveness in achieving them.' (Føllesdal 1998, 190)

For example, the subsidiarity principle is applied in the European Union, where it is meant to regulate tensions between centralization and decentralization. The principle has also been applied to legal issues (for example in international human rights law) and even in cybernetics, where it means that problems are best solved in the subsystem where they arise, without reference to a higher authority. But what happens if we apply the principle in meta-ethics? What does the principle mean in that context?

Applied to the problem at hand - which meta-ethical approach to choose subsidiarity could mean that we end up with the following methodological hierarchy, in which the different approaches I outlined function as different levels of moral analysis. First we have to explore if a moral problem can be solved by means of the exercise of natural capacities such as sympathy and cooperation, and see if that works. If not, then we have to move to higher level: rational morality. But this in turn may fail; in order to preserve "moral safety", we then have to perform a deconstructive operation that questions the deepest presuppositions of our moral systems: who are the moral agents and patients? In principle, subsidiarity could also mean that we start with one of the other levels: the point is that the problem gets solved. What matters is comparative effectivity and efficiency. Hence the proposed hierarchy is not fixed; it is changeable if it turns out that another approach is more effective and efficient. However, since higher levels of abstraction are more remote from moral experience, it is more likely that people will start at the most "local" level of abstraction, with "local" meaning here: close to moral experience and enabling the exercise of natural capacities.

For example, faced with the question whether robots have rights (see for example Gunkel 2017; Coeckelbergh 2010), we could first look at a naturalist and social science account of human-robot interaction, which can teach us something about how humans behave towards robots. If this fails to solve the problem, since as it turns out people respond very different to robots (some act as if robots are human beings or animals and exercise empathy towards them, 
whereas others treat them as machines), we have to reflect on these responses and in the end have to rely on a normative theory of obligation and moral standing, but then we soon find out that such theories are based on properties, which raises epistemological problems among others (Coeckelbergh 2012), and for instance Kantian theory is anthropocentric. Does this do enough justice to the moral experience of interacting with robots? Reflecting on this may push us to the next level, which enables us to question that anthropocentrism and the related power relations, leading to a politicization of the question and potentially to a total deconstruction and change of the initial question. The inquiry is thus, methodologically and hence meta-ethically speaking, the result of a kind of moral cascading through different meta-ethical approaches. In fact, this is in part what Gunkel and I do in our work on moral standing in robot ethics, since our initially normative moral question about the moral standing of robots turns into a meta-ethical inquiry when we ask fundamental questions concerning how humans deal with moral standing and with other human beings, and what we mean by rights in our society. The proposed meta-ethical method makes sense of this and provides also guidance for other cases.

Further support for my argument that we best start with the naturalist and social explanations (and, practically, the exercise of the relevant capacities), is that proceeding like this this seems closest to what Dewey scholars such as Fesmire (2019; 2003) and Pappas (2008) call "moral experience" and "responding to the demands of the situation." Let me elaborate how Deweyan pragmatism lends support to the proposed meta-ethical methodology.

My proposal takes inspiration from pragmatism and strengthens its argument since - in line with Dewey's pragmatism - it is geared at meeting the demands of the situation (Fesmire 2019). Like Glaucon in Plato's Republic, pragmatists view morality as a way to solve problems we face in society; this contrasts with Socrates's position that there are independent and eternal standards for moral judgment and of course with Kantian ethics. Dewey introduced a situational ethic, which starts with the situation and relies on moral experience. But here I add a particular cascading method: Faced with a particular moral challenge and using the principle of subsidiarity, the moral philosopher and, ultimately, the moral agent in the situation, will first explore if the problem can be solved by relying on capacities such as sympathy and cooperation. If this "local" solution works, then fine. However, if the demands of the situation are such that a solution can only be found if a moral framework of obligations, demands for justice, etc. is applied, then the philosopher or moral agent/decision-maker will move to that level. If this still does not enable a satisfactory solution, a higher-level discussion about power for instance 
or the boundaries of the moral community may be necessary. The cascade (or progression, if you wish) thus starts with what is closest to the moral experience of "ordinary" moral agents and then moves up to different and higher levels of abstraction. The subsidiarity principle is thus employed in this way, and the cascading architecture or hierarchy is set up in this way, in order to keep meta-ethics as close as possible to moral experience of the situation, in which we have specific morally relevant feelings and already respond in morally relevant ways using natural and social capacities such as empathy or sympathy, before other tools such as moral reasoning and postmodern theory can kick in. If this is the most effective and efficient way to deal with the moral problems we face, so the proposed meta-ethical subsidiarity principles says, then this is where our focus should be.

This way of working fits with what Anderson (2018) identifies as the naturalism in Dewey, and with the role Dewey believes imagination plays in moral reasoning (Fesmire 2003) - both of which connect back to Hume. Dewey would not reject reasoning, rationality, theory, and so on, but would stress that these are tools that help us to come with the morally difficult situation. Furthermore, a Deweyan approach has the additional advantage that it tends to work with the social sciences and the political interest of postmodern theory, for example if we consider the topic of habits, a concept used by Dewey but at least since Bourdieu also present in the social science, or the claims Dewey made about democracy, which may be of interest to those who want to perform deconstruction on this, e.g. if one wishes to ask where Dewey draws the boundaries of political membership. The proposed hierarchy and application of the subsidiarity principle in a way that starts from naturalist orientations, can thus be seen as constituting an implementation of Deweyan meta-ethical intuitions.

Response to potential objections and further discussion. One may object that the application of the meta-ethical framework to the moral agent or moral decision-maker confuses meta-ethics with making moral choices and applying normative moral theory. Meta-ethics, as understood in the analytic tradition at least, is not supposed to "work" at all. It is supposed to be a highly abstract reflection on the nature and foundation of morality. All the rest are external and empirical matters. But from a pragmatist, non-foundationalist perspective, this distinction must be deconstructed: a meta-ethics must be relevant to the making of moral choices. It is not supposed to be divorced from moral experience. Meta-ethics, like moral theory, does not give us transcendent authoritative criteria but tools that are supposed to work in practice. It corresponds to the idea of a Deweyan 'reflective' morality that is not only naturalist but also non-authoritarian and is able to adapt to change (Anderson 2018). Moreover, Dewey's idea was that morality is not just a question of individual 
reasoners; instead, we have to pursue the moral inquiry together as we try to solve the problems we face. Applied to the meta-ethical framework at hand, this means that it is not meant for individual philosophers or citizens, but has to prove its usefulness as a tool in a democratic setting. In the end, whether it is a good idea to have such a cascading (or progressing) morality framework as a meta-ethical algorithm guided by the subsidiarity principle, is a matter of experimentation.

Furthermore, because of the openings to naturalism and constructivism, movements towards collaboration with natural or social scientists are also no longer seen as involving an operation to deal with "external" elements. This distinction between internal and external, too, needs to be deconstructed. So-called "empirical" matters are to be seen as entirely internal to the business of morality in so far as they have to do with the features of the moral situation and moral experience, which can be described with the help of the natural and moral sciences and - if these theories are needed at all - can be picked up by means of Humean sentiment and imagination or postmodern sensitivities to differences, for example.

Is this position sufficiently supported now? For moral philosophy faced with societal issues and, more generally, with interdisciplinary challenges, the proof of the pudding is in the eating. Whether the proposed meta-ethics works as a framework that can help moral philosophers respond to the challenges coming from other disciplines, depends not on theory but indeed on whether it works, that is, on what it can do to deal with these issues. For example, to the naturalist challenges coming from the neurosciences, from biology, and from social psychology, a moral philosopher can reply that if it is the case that human beings have capacities for cooperation, solidarity, and so on, then this will help us to understand and cope with some moral issues in some situations, but that other meta-ethical tools may be necessary in other situations. For example, when dealing with moral choices in a pandemic and reflecting on what moral framework to use, one could rely on natural capacities of people for cooperation and solidarity, but if it turns out that this is not enough, it will be necessary to appeal to notions of justice and/or other principles from rationalist moral theory. And if such arguments fail to do what they are supposed to do (deal with the moral situation), then one should politicize the problem and one might question, for example, the ways power is distributed in our society and the way we organize democracy. As suggested previously, the proposed meta-ethical method thus provides a kind of algorithm for working through potential moral frameworks, faced with a specific situation.

Note that taking the next step in the algorithm (or going down the next step in the cascade) does not at all mean that the other approaches do not make 
sense or are useless. Often they remain useful; there is no exclusivity. Usually there is a cumulative dynamic at work. If the situation so demands, one may have to add the next approach(es). For example, using moral principles does not exclude making observations about the moral imagination people use to deal with the situation. However, applying the subsidiarity principle means that if one does not need another approach to handle the moral problem then one stops. For example, if sympathy or imagination were enough to deal with problems in animal ethics, then one would not need elaborate moral theories of animal rights or deconstructions of the anthropocentrism inherent in our traditional moral theories. As it turns out, an account based on sympathy is not enough. But in principle one could imagine a situation where a Humean approach or, more generally, a naturalist or social approach is entirely satisfactory to deal with the situation and indeed to understand how people are already dealing with the situation, for example when feelings of approval and disapproval are sufficient to regulate relationships in a family context, without a need for explicit moral reasoning. Similarly, one could imagine that a direct political approach can be appropriate in some situations, for instance when women are obviously excluded from a morally relevant procedure; an argument based on rights or an observation about how something is displeasing may then be out of place.

Yet often a direct moral response to a situation in terms of sentiments or action may already solve the problem. Moral philosophy, understood in the strict Kantian rationalist sense as explicit moral reasoning based on rational considerations and theories rather than reflection on our feelings and on what goes on in naturalistic and social terms, is an emergency aid; if we don't need it we can ignore it. We just have to know it in case, like the safety instructions or life vests in an airplane. And if we can do without the deconstructions offered by the third approach, why not? The subsidiarity principle is used here as a way to keep dealing with moral issues economical. If the problem is solved by one approach, then that is all we need. There will sufficient new problems; we better save our individual and collective energy for the next one and the bigger ones. We just have to learn all the approaches - as moral philosophers and as highly developed moral agents in general - in order to be equipped for the worst cases. If we are lucky, the natural and social capabilities we already have will help us to make some progress, but there is always the risk of failure; the rest we have to learn and we have to prepare and be prepared. I use the plural "we" because moral problems are faced in a societal context. To use a Deweyan term: solving moral problems it is a matter of collective intelligence. And it is always a risky business. Neither the situation nor whether we succeed is entirely under our control. This is why we need a good multi-layered safety 
architecture: one that does not rely on one tool but on several, and one that has enough "safety nets" or "backup systems".

Next to responsiveness to experience and the situation, the point that the meta-ethical method is guided and governed by a principle that brings order in the pluralist architecture is also a way to counter the charge of "anything goes" relativism, an objection which is often raised against postmodernism and which may also be brought against meta-ethical pluralism. It is not the case that "anything goes" when it comes to meta-ethical choices. The demand to be responsive to the situation and the application of the subsidiarity principle give a preference to some approaches rather than others and put clear methodological constraints on their application. If there is a relativism at all, it means that the use of moral theory will depend on, and be relative to, the demands of the situation - similar to what Dewey proposed with regard to normative moral theory but then applied to meta-ethics. And the application of the subsidiarity system is also relative in the sense of "situational", since whether or not the problem can be dealt with sufficiently at one level and by use of one theory is itself dependent on the situation and the moral experience in that situation. Thus, there is a type of relativism at work, but there is no implication that anything goes. I propose a clear methodology that leads to a specific preference on the basis of a principle that guides and constrains the choice and use of moral theory. As said, it is a kind of algorithm that prescribes steps to follow.

Yet it needs to be stressed that, in line with Dewey's ethics and in contrast to some modern ethics, the proposed model is not to be understood as what Pappas calls 'a mechanical decision procedure by which we can solve all problems. (Pappas 2008, 73) This is why the algorithm metaphor only partly works and could potentially be misleading. Whereas in cybernetics the subsidiarity principle may well be applied more rigidly, for example in the software architecture of the controller of a robot, in a meta-ethics inspired by Dewey this level of rigidity is out of place. Remaining open to experience means that if the demands of the situation change and are such that it is better to start from one of the other approaches or from a different, fourth approach altogether, then that is fine. Conceiving of this meta-ethical approach as an instrument implies that there is always the possibility that there is another, better instrument, or that the instrument can be improved. But I do think that the instrument proposed here can give meta-ethical guidance in many cases. In the end, experience will tell. But there is always the possibility of failure. And some moral problems may well be tragic, as Pappas has pointed out: often we are torn between irreconcilable obligations (92). There is not always a final and satisfying solution. This is not only true for moral decision making but also for meta-ethical inquiry. Therefore, meta-ethics must proceed with caution and 
humility. Anyone applying the model may fail to deal with the problem. And, to apply these meta-ethical virtues at an even higher meta-level of analysis: it may well turn out that I am wrong about the model I have proposed. The appropriate response is then that the tool needs to be refined or that another tool is better.

\section{Conclusion: Dirty Morality, Meta-Ethics as Instrument, and the Usefulness of the Proposed Methodology for Interdisciplinary Moral Philosophy}

While the full execution of this project goes beyond the scope of this paper, I have at least provided some support for the argument that if we care at all about a morality that works, we need not only a pluralist but also a cascading (or upwardly progressing) model of morality that involves a subsidiarity hierarchy for dealing with meta-ethical questions. This constitutes an original and novel application of the subsidiarity principle, which is usually applied to social and political organization.

Whether it works it practice as a tool for dealing with theory variety and indeed for dealing with moral problems, is - as explained - ultimately a matter of experimentation and discussion faced with a concrete situation. The model also needs further theoretical elaboration. But I have offered some examples how it is already working with regard to some specific moral issues and I have shown that as a conceptual tool, the model can be developed and justified by relying on Deweyan pragmatism and the principle of subsidiarity.

This paper has also argued that the Deweyan understanding of moral theory as a tool also extends to meta-ethics. Perhaps to the horror of Kantians, I conclude that meta-ethics itself must be understood as an instrument. It is true that meta-ethics is also discourse. And if needed we can move to very abstract and even formal levels of analysis. We have the words. We have the discourse. We have the language. But the answers we give to the questions what morality is and what the foundation of morality is should, in the end, be useful. Therefore, one could also say: we have the tools. And these tools should be geared to the moral experience and situation. From a Deweyan perspective, a pure meta-ethics, that is, one that is purified from moral experience and based on foundations that are supposed to be entirely external to that moral experience, is neither possible nor desirable, if not dangerous. If we are to exercise our responsibility as moral philosophers, we have a meta-ethical duty to keep it dirty.

Understanding meta-ethics as an instrument also enables us to understand why a meta-ethics can and must be pluralist. In order to find the right tool for 
a specific problem, we need experience and we also need a good toolbox, containing not just one but several tools. If not only morality but also meta-ethics is a risky business, we are better prepared.

This approach, then, does not only have good arguments for it as a general meta-ethical model but is also more likely to succeed when, as moral philosophers, we engage with other disciplines in the natural and/or social sciences and even with technological fields such as engineering. Since the pluralist model includes naturalist and constructivist directions, it is able to interface with the natural and social sciences, and its problem-oriented and situation-oriented Deweyan approach to morality fits better with general engineering methodology than, say, a Humean psychologizing or a Kantian rationalization of morality.

In addition, and for the same reasons, within philosophy it is also able to take on interdisciplinary challenges, for example in dialogue with philosophy of science or postmodern philosophies. As most moral philosophers will agree, moral philosophy is not supposed to be isolated from other fields within philosophy. The proposed meta-ethical model offers chances to do this.

Now one could rightly argue that with regard such collaborations with other fields and with other subfields within philosophy, the subsidiarity principle should also be applied: if it can be done within the (sub)discipline, then fine. But if not, here is a model that creates some space to do so - space which is often hard to find, if not lacking, in non-pluralist meta-ethics. Given the complex problems we are facing a society, my guess is that we will badly need those spaces for interdisciplinary normative inquiry. Therefore, we better develop the meta-ethical tools that can create these spaces and enable moral philosophers and others to operate effectively in them. We need new discourses and new toolboxes.

Finally, as moral philosophers employ their meta-ethical tools, they need to be aware of the different languages and discourses that are used within the relevant approaches and fields, treating them, as it were, as different cultures. Without this awareness, it is not possible to carry out the necessary interpretations and translations for a truly pluralistic approach. For example, if, in a given situation, I come to understand that a more rational or political approach can help to deal with the situation, I may still need to be able to understand, interpret, and translate concerns voiced by philosophers arguing within a different meta-ethical approach. If I fail to do this, I may not succeed in solving the situation. Moral problems and meta-ethical problems are also in part communication problems. In the real world I have to argue why I believe the approach I propose works better and has value in the light of subsidiarity. I have to understand what others mean and I have to try to convince them. This argumentative and communicative requirement is true for moral 
arguments but also for meta-ethical arguments. And this requires that I also learn to understand other discourses and to use other tools than the ones I am used to because of my particular philosophical training. One of the lessons we can learn from both analytic and continental philosophy of language is that philosophy, and hence also meta-ethics, is also - but not only - about rhetoric, linguistic performances, metaphors, narratives, and so on. As moral philosophers, we have to be aware of this and respond critically to their uses a response which itself necessarily takes place within language. Hence language-related instruments, too, must part of the toolbox of the interdisciplinary philosophers dealing with meta-ethics. To develop this point, however, is beyond the scope of this paper.

\section{References}

Anderson, Elizabeth. 2018. "Dewey's Moral Philosophy," In Stanford Encyclopedia of Philosophy, Retrieved 6 May 2020 https://plato.stanford.edu/entries/dewey-moral/. Coeckelbergh, Mark. 2010. "Robot Rights? Towards a Social-Relational Justification of Moral Consideration," Ethics and Information Technology 12(3): 209-221.

Coeckelbergh, Mark. 2012. Growing Moral Relations: Critique of Moral Status Ascription. Palgrave Macmillan.

Dennett, Daniel. 2003. Freedom Evolves. New York: Viking Press.

Dewey, John. 1930. "Three Independent Factors in Morals," in Dewey, John, The Later Works Vol. 5 (1925-1953), ed.J.A. Boydston. (Carbondale:Southern Illinois University Press), 1981.

Fesmire, Steven. 2003. John Dewey and moral imagination: Pragmatism in ethics. Bloomington and Indianapolis: Indiana University Press.

Fesmire, Steven. 2019. "Beyond Moral Fundamentalism: Dewey's Pragmatic Pluralism in Ethics and Politics," in, Steven Fesmire, ed. The Oxford Handbook of Dewey. (Oxford: Oxford University Press).

Føllesdal, Andreas. 1998. "Survey Article:Subsidiarity," The Journal of Political Philosophy 6(2): 190-218.

Foucault, Michel. 1980. Power/knowledge: Selected interviews and other writings, 1972-1977. New York: Pantheon Books.

Gewirth, Alan. 1968. "Metaethics and Moral Neutrality," Ethics 78(3): 214-225.

Gunkel, David. 2017. “The Other Question: Can and Should Robots Have Rights?” Ethics and Information Technology 20: 87-99.

Haraway, Donna. 1991. "A Cyborg Manifesto," in, D. Haraway Simians, cyborgs, and women: The reinvention of nature. (New York and Abingdon, Oxon: Routledge). 
Hume, David. 1751. "An Enquiry Concerning the Principles of Morals." In, D. Hume Enquiries Concerning Human Understanding and Concerning the Principles of Morals. Reprinted from the 1777 edition. Third edition. (Oxford: Clarendon Press), 1975 .

Johnson, Robert and Adam Cureton. 2016. "Kant's Moral Philosophy," in Stanford Encyclopedia of Philosophy, Retrieved 6 May 2020 https://plato.stanford.edu/ entries/kant-moral/\#AimMetMor.

Kant, Immanuel. 1785. Groundwork for the Metaphysics of Morals. Ed. and trans. Allen W. Wood . New Haven and London: Yale University Press, 2002.

Nussbaum, Martha C. 2006. Frontiers of Justice: Disability, Nationality, Species Membership. Cambridge, MA and London, England: Harvard University Press.

Pappas, Gregory F. 2008. John Dewey's Ethics: Democracy as Experience. Bloomington and Indianapolis: Indiana University Press.

Plato. Republic. In, B. Jowett, ed. trans. The Dialogues of Plato Vol. II. Oxford: The Clarendon Press, 1953.

Smith, Adam. 1759. The Theory of Moral Sentiments, eds. D.D. Raphael and A.L. Macfie. Oxford: Oxford University Press. 